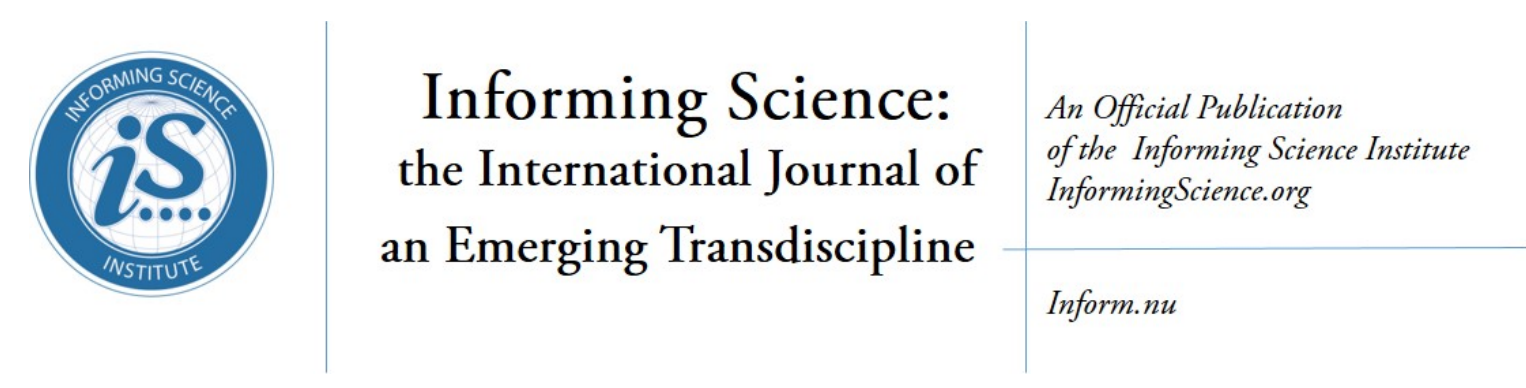

Volume 21, 2018

\title{
COMPLEXITY LEADERSHIP THEORY AND THE LEADERS OF TRANSDISCIPLINARY SCIENCE
}

Elina I. Mäkinen
University of Tampere, New Social

Research Program and Faculty of

Management, Tampere, Finland elina.i.makinen@uta.fi

\begin{abstract}
Aim/Purpose Given that leadership has been shown to play a key role in knowledgeproducing organizations, leaders of transdisciplinary science have received surprisingly little empirical attention. This study addresses the research gap by examining leadership in the context of a new transdisciplinary research organization.
\end{abstract}

Background Drawing on complexity leadership theory — a framework developed for identifying behaviors that facilitate creativity, learning, and adaptability in complex adaptive systems - this study examines leadership roles and practices that affect the generation of adaptive dynamics in transdisciplinary science.

Methodology The study is based on a longitudinal, qualitative in-depth case study on a newly formed transdisciplinary research center and its leadership team. The data includes ethnographic observations from leadership meetings and interviews with leaders.

Contribution This unique empirical case contributes to the study of transdisciplinary science by shedding light on the actions of academic leaders as they try to support transdisciplinary conversation, learning, and collaboration in a new center.

Findings The analysis shows that the leaders relied on both enabling and administrative leadership practices in a way that made them the focal point of transdisciplinary knowledge integration and thus jeopardized the creation of adaptive dynamics throughout the organization.

Recommendations The study highlights the importance of having knowledge brokers and hybrid for Practitioners scholars in strategic positions at different levels of the transdisciplinary research organization already in its early stages.

This paper is one in a Special Series on Transdisciplinary Communication

Accepting Editor Gaetano Lotrecchiano | Received: September 29, 2017 | Revised: March 17, March 24, 2018 | Accepted: April 9, 2018.

Cite as: Mäkinen, E. I. (2018). Complexity leadership theory and the leaders of transdisciplinary science. Informing Science: the International Journal of an Emerging Transdiscipline, 21, 133-155. https://doi.org/10.28945/4009

(CC BY-NC 4.0) This article is licensed to you under a Creative Commons Attribution-NonCommercial 4.0 International License. When you copy and redistribute this paper in full or in part, you need to provide proper attribution to it to ensure that others can later locate this work (and to ensure that others do not accuse you of plagiarism). You may (and we encourage you to) adapt, remix, transform, and build upon the material for any non-commercial purposes. This license does not permit you to use this material for commercial purposes. 
Recommendation Longitudinal qualitative case studies that rely on different types of data provide for Researchers rich information on how new leadership conceptualizations are implemented in organizations and the complex ways in which they relate to knowledge creation processes and outcomes.

Impact on Society Transdisciplinary science has the potential to find cures to complex diseases. Understanding leadership in transdisciplinary science can help in maintaining transdisciplinary research activities in the long run and thus make it more impactful.

Future Research The use of leadership roles and practices will be examined at different developmental stages in the transdisciplinary research process.

Keywords transdisciplinary science, medicine, collaboration, research center, complexity leadership theory, knowledge integration

\section{TRANSDISCIPLINARY SCIENCE AND THE ROLE OF LEADERS}

Academic institutions, foundations, and governments have been investing in research consortiums that promote the mixing of disciplines (Boix Mansilla, 2006; Jacobs \& Frickel, 2009). At first, these research organizations were said to rely on interdisciplinary research approach. More recently, the rhetoric used to describe innovative science has moved from interdisciplinarity to transdisciplinarity. Initially, the notion of transdisciplinary science was related to Mode-2 knowledge production, a term developed by Gibbons et al. (1994). The Mode-2 approach emphasized the applicability and the societal value of scientific findings (Gibbons et al., 1994; Ziman, 1996). Transdisciplinary science, more so than interdisciplinary research, tends to be directed at solving complex problems, which may enhance the practical value of research findings (Maasen \& Lieven, 2006). It has been noted that transdisciplinary research efforts can result in a larger synthesis and the formation of a new intellectual community that is focused on an identifiable topic (Stevenson et al., 2013).

Transdisciplinary research collaborations have developed at such an increasing rate that researchers interested in how they should be managed have had a difficult time keeping up. This is concerning given that the multidisciplinary, collaborative, and multi-organizational nature of scientific research demands a type of academic leadership that is able to nurture collaboration across different kinds of experts and knowledge boundaries (Shrum, Genuth, \& Chompalov, 2007; Sonnenwald, 2007).

In the context of nonacademic organizations, leadership researchers have declared that the relationships between leaders and organizational members matter a great deal for how organizations perform (Barge \& Musambira, 1992). Moreover, both theoretical and empirical contributions in leadership research have demonstrated that leadership plays a key role in knowledge creation processes in nonacademic organizations (Bryant, 2003; Lakshman, 2007; Politis, 2002; Srivastava, Bartol, \& Locke, 2006). Yet, the role of leaders in institutions of higher education has attracted little empirical attention (Bryman, 2007).

This study addresses the research gap by examining, what kind of leadership roles and practices academic leaders of transdisciplinary science draw on when seeking to promote emerging transdisciplinary collaboration. The study utilizes the framework of complexity leadership theory, which has been developed to understand complex adaptive systems. Complex adaptive systems are places for actors to engage in knowledge-intensive cooperation in a collaborative network that has a common goal (e.g., Hazy, 2007; Marion \& Uhl-Bien, 2001; Uhl-Bien, Marion \& McKelvey, 2007). Transdisciplinary research organizations can be characterized as complex adaptive systems because they similarly bring together actors from varied backgrounds, promote interdependence among them, and form dynamic collectives with common goals (Cilliers, 1998; Lotrecchiano, 2010; Marion, 1999). Understanding leaders and their actions in complex adaptive systems in academic contexts is important, because 
leaders can be characterized as the "catalysts that possess the ability to affect organizational learning through social interactions in countless ways" (Lotrecchiano, 2010, p. 56).

Importantly, those leading transdisciplinary research in academic contexts face particular challenges. First, cross-disciplinary research units are different from discipline based departments. Biancani, McFarland, and Dahlander (2014) defined interdisciplinary research centers as semiformal organizations that are temporary and fluid, and where participation is voluntary. The authors argued that university departments, in comparison, are formal units where organizational memberships are assigned as a term of employment. These disciplinary and departmental communities offer their members safety, familiarity, and a clear understanding of academic norms (Abbott, 2001). Instead, transdisciplinary collaboration requires that scholars view knowledge creation beyond their disciplinary units and consider the goals of a broader knowledge system (Klein, 1990). Therefore, leaders of transdisciplinary science have to attract scholars from departmental to transdisciplinary units and support their voluntary participation in the shared, transdisciplinary research endeavor.

Once leaders of transdisciplinary science have succeeded in attracting talented scholars across departments, they face another leadership challenge: how to motivate scholars to interact across disciplinary boundaries. Some have conceptualized this challenge as one of cognitive incommensurability (Cummings \& Kiesler, 2005; Dougherty, 1992; Lamont, 2009; Murray, 2010). Collaborators' different disciplinary orientations, motivations, and professional interests can come in the way of effective collaboration. These challenges are highlighted in transdisciplinary science, because it tends to bring together not only academics from different disciplines, but also non-academic actors, such as practitioners, policymakers, and industry representatives, who all have their own reasons to participate (Maasen \& Lieven, 2006).

As a third challenge, after researchers are in place and collaborating in the transdisciplinary research organization, leaders of transdisciplinary science have to manage the tension between the need to innovate and the need to produce (Uhl-Bien \& Arena, 2018). In order to survive, complex adaptive systems, such as transdisciplinary research organizations, have to produce innovative knowledge rapidly (Uhl-Bien et al., 2007). The creation of innovative outcomes requires risk taking, experimentation, and play (March, 1991). This can create a tension in a transdisciplinary research organization, because the familiar disciplinary research approach may appear as a faster path to productivity. In relation to their work on leadership and organizational adaptability, Uhl-Bien and Arena have noted (2018, p. 11) that it is important not to let "the pressure to produce overwhelm the need to innovate." Leaders of transdisciplinary science, then, need to make sure that scholars do not fall back on their disciplinary ways of creating knowledge when there is pressure to produce outcomes.

This study considers how academic leaders address these challenges and support transdisciplinary collaboration in a unique empirical setting: a newly formed transdisciplinary research organization in the field of medicine. The research center was formed through a partnership between a School of Medicine and a non-profit foundation. It brought together physicians, medical researchers, and scientists from different fields to study a problem — premature birth — that had been researched from different disciplinary perspectives for decades and yet, never solved. Premature birth could be characterized as an adaptive challenge: solving it would require new learning, innovation, and new patterns of behavior (Heifetz, 1994; Heifetz \& Linsky, 2002).

The data for the study consists of ethnographic observations from leadership meetings collected over the course of three years and interviews with the leaders at two different time points. I draw on this data to develop an in-depth, longitudinal qualitative case study on the work of leaders of transdisciplinary science (Yin, 2009).

The findings demonstrate that when it comes to attracting researchers from different disciplinary backgrounds to collaboratively advance knowledge on a single research problem, the leaders of transdisciplinary science rely on different leadership roles and practices present in the complexity leadership framework (Hazy \& Uhl-Bien, 2013; Uhl-Bien et al., 2007). At first, the leaders drew on 
practices related to enabling leadership. They brought organizational members' diverse perspectives together by forming heterogeneous project teams. Next, they modelled transdisciplinary behavior and took on roles as knowledge translators and brokers.

While brokering and bridging practices have generally been shown to support innovation, in the context of the center, these activities began to reinforce administrative-instead of enabling-leadership (Lomas, 2007; Ward, House, \& Hamer, 2009; Waring, Currie, Crompton, \& Bishop, 2013). The leaders decided on promising research ideas, how resources were used, and assigned experts on projects. These administrative practices made the leaders the focal point of transdisciplinary knowledge integration and thus hindered the creation of shared adaptive dynamics.

The paper is organized as follows. Next, I describe the main aspects of complexity leadership theory as it frames the analysis of leadership roles and practices in the new transdisciplinary research center. Then I describe the empirical setting, data collection, and data analysis. The empirical analysis covers the different roles and practices the leaders relied on when mobilizing transdisciplinary collaboration in and outside of meetings. I conclude with a discussion on what complexity leadership theory can add to our understanding of transdisciplinary science and the role of academic leaders.

\section{CONCEPTUALIZING LEADERSHIP IN TRANSDISCIPLINARY SCIENCE}

As organizations have become more knowledge-intensive and as they operate in an increasingly fastpaced environment, the traditional leadership models, often bureaucratic and centralized in nature, have been seen as insufficient (Marion \& Uhl-Bien, 2001; Schneider \& Somers, 2006). Scholars have raised the question, to what extent can traditional leadership models support modern organizations, where the main purpose is to create innovative products by combining the expertise of different individuals? As a result, leadership researchers have begun to consider leadership as practices distributed throughout the organization rather than as actions of a few leaders at the top-level of the organization (Hargadon, 2003; Pearce \& Sims, 2000; Yukl, 2005). The new theories emphasize a relational kind of leadership that focuses on dynamic and interactive social processes occurring throughout the organization (Drath, 2001; Uhl-Bien, 2006).

Building on this work, scholars have developed new conceptualizations of leadership that are grounded in complexity theory (Hazy, 2007; Lichtenstein et al., 2006; Marion \& Uhl-Bien, 2001; UhlBien et al., 2007). The purpose of this research has been to understand what leadership means in knowledge-intensive complex adaptive systems, where individuals collaborate and share a common goal. In this context, leadership has been seen as dynamically evolving, emergent, and distributed (Bolden, 2011; Dervitsiotis, 2005).

\section{COMPLEXITY LEADERSHIP THEORY: ROLES AND PRACTICES}

Complexity leadership theory perceives leadership as an interplay between many forces: administrative, enabling, and adaptive leadership (Marion \& Uhl-Bien, 2001; Uhl-Bien et al., 2007). In order to create effective adaptive dynamics - that is, the generation of creative knowledge that exhibits significance and impact-finding a balance between different leadership roles is seen as important.

The first, administrative leadership, resembles the traditional, bureaucratic, and hierarchical type of leadership (Uhl-Bien et al., 2007). It is said to include practices such as building vision, implementing strategy, and assigning work responsibilities (Hazy \& Uhl-Bien, 2013). While these are often seen as strategies for building stable organizations, complexity leadership theory recognizes their importance for creating managed chaos (Nag, Corley, \& Gioia, 2007; Uhl-Bien \& Marion, 2009). After all, the goal is not to spin out of control, but to stimulate innovation and creativity in a way that is in line with organizational goal (Dess \& Picken, 2000). In their most recent work on organizational adaptability, Uhl-Bien and Arena (2018) have argued that administrative leadership should be relabeled as 
operational leadership, which focuses on how formal leaders enable the production of results through selection, execution, and efficiency.

The second, enabling leadership, operates between administrative and adaptive leadership and it draws attention to the ways in which leaders can structure conditions that are optimal for problemsolving, adaptability, and new learning (Uhl-Bien \& Marion, 2009; Uhl-Bien et al., 2007). It involves building an environment where diversity is appreciated and work groups are structured to enable interaction and collaboration. Enabling leaders are individuals who adopt behaviors for enhancing interactive and adaptive dynamics (Uhl-Bien \& Arena, 2018). They can, for example, act as brokers who bring individuals, ideas, and resources together and support exchange of information (Arena, Cross, Sims, \& Uhl-Bien, 2017; Uhl-Bien \& Arena, 2018). They also monitor the organization to better understand the different forces influencing the emerging adaptive dynamics.

The third, adaptive leadership, is a complex dynamic rather than a role assigned to a person. It is an interactive type of leadership that underlies emergent change activities. Ultimately, all heterogeneous knowledge-producing organizations should strive for adaptive dynamics and adaptive leadership. As the authors noted: "adaptive change is produced by the clash of existing but (seemingly) incompatible ideas, knowledge, and technologies; it takes the form of new knowledge and creative ideas, learning, or adaptation" (Uhl-Bien et al., 2007, p. 307). However, later Uhl-Bien and Arena (2018) argued that a better label for adaptive leadership was entrepreneurial leadership, which emphasizes the creation of new knowledge, skills, products, and processes in order to sustain the organization's success in the long run.

What is unique about the complexity leadership theory is that it does not ignore or deny the influence of traditional and bureaucratic tendencies. Instead, it suggests that by mobilizing enabling leadership, it is possible to find an optimal balance between administrative and adaptive forces. While administrative or operational, enabling, and adaptive or entrepreneurial leadership roles are described in different terms, they are all simultaneously present, entangled, and interdependent when leaders seek to facilitate innovation (Kontopoulos, 1993; Uhl-Bien et al., 2007).

\section{CONNECTING ACTIVITIES}

Complexity leadership theory framework highlights the importance of connecting activities that can link ideas, information, people, resources, and technology in ways that scale novelty and innovation (Uhl-Bien \& Arena, 2018). Connecting activities are typically associated with enabling leadership. In practice, these activities may include knowledge brokering, joint training opportunities, and shared decision-making. Connecting activities are critical in the facilitation of adaptability and change in knowledge-intensive organizations (Arena et al., 2017; A. Taylor \& Helfat, 2009; Uhl-Bien \& Arena, 2018).

Indeed, knowledge brokering and bridging have been shown to foster learning and innovation in different professional contexts, for instance in healthcare settings (Lomas, 2007; Ward et al., 2009; Waring et al., 2013). While boundary spanning in collaborative knowledge work is known to be important, it has also been shown to be difficult to accomplish (Bechky, 2003; Haas, 2006; Huising, 2014; Kellogg, 2014; Majchrzak, More, \& Faraj, 2012). In transdisciplinary contexts, a significant challenge is that the number of different boundaries is relatively high as collaborators come from, for example, academia, industry, and policy sectors. Furthermore, no matter which sector they come from, individuals have varying capabilities to facilitate boundary-crossing (Lotrecchiano, 2010, 2014; Uhl-Bien et al., 2007).

In relation to these challenges, Uhl-Bien and Arena (2018) have noted that in complex adaptive systems connecting will co-occur with conflicting. In other words, conflicts are inevitable, but they can be productive if leaders simultaneously help individuals connect across differences and link up around adaptive responses (Arena et al., 2017). Both adaptive and enabling leadership can play a role in how conflicts are managed. According to Lotrecchiano (2010), adaptive leadership strives to de- 
velop collaborators' conflicting ideas and perspectives into resolute outcomes. Enabling leadership, in turn, fosters interactions and interdependency and in this way supports the interactive and adaptive dynamics of complex systems.

\section{METHODS}

This study draws on a longitudinal qualitative research project on a new transdisciplinary research center in the field of medicine. A team of social scientists, which the author was part of, was given access to study the center, because the leaders of the transdisciplinary research organization were convinced that a sociological understanding of the center's evolution would provide important insights on how the conduct of transdisciplinary science developed over time.

The transdisciplinary research center was located in a research university in the United States. The center was formed through a partnership between the university's School of Medicine and a nonprofit foundation. Senior scholars from the School of Medicine-who later became the center's leadership team-wrote a research proposal to form a transdisciplinary research center focusing on premature birth. The center's mission was to create new knowledge about premature birth through a transdisciplinary team science approach. The goal was to study and understand what leads to premature birth and ultimately translate this research into clinical interventions and policy changes.

The initial organizational setup included four transdisciplinary research teams, a data collection team, and a leadership team. Each of the transdisciplinary research teams had a methodological focus based on the team leader's research area and laboratory, but whose participants came from different disciplines.

The team of social scientists collected data on the center for almost three years since its formation in the summer of 2011. The team observed and recorded all of the meetings the center organized during this time for different teams: four transdisciplinary research teams, data collection team, and leadership team. This study focuses on observations from the leadership meetings and interviews with the leaders, but the analysis is also influenced by the author's broader understanding of the center's transdisciplinary work and how it evolved over time (Mäkinen, 2015).

\section{FOUR TRANSDISCIPLINARY RESEARCH TEAMS AND A DATA COLLECTION TEAM}

The center had four transdisciplinary research teams: placenta team, premature birth pattern team, bioinformatics team, and microbiome team. Table 1 characterizes the four teams according to their focus, core research fields, and types of data the scientists worked with.

First, the placenta team studied the role of placental cells in premature birth and focused on cases of placental failure. The team leader was a geneticist and her main collaborators (four women) came from the fields of genetics, OB-GYN, and pathology. During the data collection period, the team organized only four meetings and each of them lasted about 90 minutes. Funding for the project was cut after the first year and the reasons for these outcomes are analyzed in a separate study.

Second, the premature birth pattern team identified geographical and temporal premature birth trends in the United States birth record dataset by using cluster analysis approaches. The team was led by a computer scientist and the team members (six men and one woman) included statisticians, epidemiologists, and clinicians and medical researchers from OB-GYN, neonatology, and pediatrics. During the data collection period, the team organized 28 meetings, which lasted about 90 minutes each.

Third, the bioinformatics team studied which biological markers were associated with pregnancy related diseases. The team was led by a bioinformatician and most of the project's analytical work was done by bioinformaticians (two men and one woman). However, there were also clinicians and medical researchers from OB-GYN and pediatrics who regularly attended meetings and contributed 
to the project (three men). During the data collection period, the team organized 12 meetings, each meeting lasting about 90 minutes.

Fourth, the microbiome team explored how changes in the mothers' microbial communities over the course of pregnancy contributed to premature birth. The team was led by a microbiologist and its members included scientists from microbiology, immunology, and epidemiology (four men and one woman). During the data collection period, the team organized five meetings, which lasted 90 minutes each. As for the first 18 months into the project the team had to focus on collecting microbiome samples from pregnant women, most of their research activities were discussed in the data collection meetings. These meetings were organized 31 times and each meeting lasted about 90 minutes.

Table 1: Overview of the transdisciplinary teams.

\begin{tabular}{|l|l|l|l|l|}
\hline & Placenta Team & $\begin{array}{l}\text { Premature Birth } \\
\text { Pattern Team }\end{array}$ & $\begin{array}{l}\text { Bioinformatics } \\
\text { Team }\end{array}$ & $\begin{array}{l}\text { Microbiome } \\
\text { Team }\end{array}$ \\
\hline Focus & $\begin{array}{l}\text { Studying the role } \\
\text { of placenta in } \\
\text { premature birth }\end{array}$ & $\begin{array}{l}\text { Identifying geo- } \\
\text { graphical and } \\
\text { temporal prema- } \\
\text { ture birth trends } \\
\text { in the United } \\
\text { States }\end{array}$ & $\begin{array}{l}\text { Examining biolog- } \\
\text { ical markers asso- } \\
\text { ciated with preg- } \\
\text { nancy related dis- } \\
\text { eases }\end{array}$ & $\begin{array}{l}\text { Investigating the } \\
\text { relationship be- } \\
\text { tween pregnant } \\
\text { woman's bacterial } \\
\text { communities and } \\
\text { birth outcomes }\end{array}$ \\
\hline Core Fields & $\begin{array}{l}\text { Genetics; Obstet- } \\
\text { rics-Gynecology; } \\
\text { Pathology }\end{array}$ & $\begin{array}{l}\text { Statistics; Com- } \\
\text { puter science; } \\
\text { Obstetrics- } \\
\text { Gynecology; Pedi- } \\
\text { atrics; Epidemiol- } \\
\text { ogy; Neonatology }\end{array}$ & $\begin{array}{l}\text { Bioinformatics; } \\
\text { Obstetrics- } \\
\text { Gynecology; Pedi- } \\
\text { atrics }\end{array}$ & $\begin{array}{l}\text { Microbiology; } \\
\text { Immunology; } \\
\text { Epidemiology }\end{array}$ \\
\hline Data & $\begin{array}{l}\text { Stored placental } \\
\text { tissue samples }\end{array}$ & $\begin{array}{l}\text { The United States } \\
\text { birth record da- } \\
\text { taset }\end{array}$ & $\begin{array}{l}\text { Publicly available } \\
\text { biological sample } \\
\text { repositories }\end{array}$ & $\begin{array}{l}\text { Weekly sampling } \\
\text { of women's body } \\
\text { sites }\end{array}$ \\
\hline
\end{tabular}

Because the transdisciplinary research center did not have its own building, the meetings became an important strategy for supporting collaboration across disciplines. The regularly organized meetings were opportunities for interaction as well as contexts for influencing how researchers should behave as members of the new transdisciplinary research organization (Kunda, 1992; Owen-Smith, 2001). As all the center related meetings were scheduled for Wednesdays, that day became quickly known as "Prematurity Wednesday". The meetings were also organized in the same seminar room, so the space became associated with center related activities. These features helped create a sense of belonging among the researchers.

When observing the meetings, social scientists arrived to the seminar room in a similar manner as the other meeting attendees. Before the meetings began, they found a seat around the oval-shaped table or in a chair located by the walls of the seminar room, depending on how crowded the room was. Like many of the participating researchers, the social scientists used laptops for notetaking. The notetaking practice followed the well-known ethnographic method: systematic jotting down and writing up observations (Emerson, Fretz, \& Shaw, 1995). In addition, behaving in this way in the meetings, the social scientists became seen as the usual, although silent, participants who never missed a meeting. 


\section{Analysis of meeting data}

The research strategy for analyzing the meeting data was in line with ethnography of communication. Ethnography of communication allows for inductive analysis of the naturally occurring discourse of the organizational scene (B. C. Taylor \& Trujillo, 2001). It involves identifying a unit of communication practice for analysis, such as meeting talk, and then generating data about that practice through, for instance, observation, recording, and interviewing. Scholars who study meeting talk often supplement their analysis with ethnographic observation, as was done in this case (Schwartzman, 1989).

Furthermore, meeting talk in the context of the four transdisciplinary research teams was analyzed chronologically to capture how transdisciplinary science and the teams' collaborative processes developed over time. In other words, data on each of the 49 meetings were analyzed in order to capture relations between events, decisions, and actions over the course of the study period (Langley, 1999).

\section{LEADERSHIP TEAM}

As part of this previously described project on the transdisciplinary research center, data was collected also on the leadership team. This data has not been analyzed before the present study, however.

The center's leadership team consisted of five senior academics (all male) and one administrator (female). The academics represented different medical and scientific fields. They were tenured and established scholars in neonatology, pediatrics, OB-GYN, and epidemiology.

The leaders had certain objectives for jumpstarting transdisciplinary collaboration in the center. First, it was essential to create a context for transdisciplinary conversations that went beyond the established lines of research that had dominated premature birth investigation for decades. Second, the shared team meetings were seen as the most likely context in which transdisciplinary interactions would take place. These meetings allowed the leaders to monitor how transdisciplinary collaboration was progressing and use different leadership roles and practices to promote the creation of adaptive dynamics.

In an effort to exchange ideas and plan the center's activities, the leaders organized weekly meetings also for their own group. The meetings were always held at the same time and on the same day in the seminar room located at the School of Medicine. In these meetings, the leaders discussed issues relating to the management of the center. In their leader roles, they were responsible for a number of things, such as:

- making sure scientific progress was made in each team

- identifying and attracting new talents into the teams

- mentoring junior researchers

- fundraising together with the foundation

- preparing annual progress reports

- determining annual research budgets

While important decisions were discussed among the whole leadership team, certain roles and tasks were given to individual leaders. As there were four transdisciplinary research projects to oversee, the leaders for instance divided the responsibilities of attending different project meetings. Similarly, some leaders worked more closely with the representatives of the foundation than others. Different tasks were divided according to each leader's interests and capabilities.

\section{Observing the leadership meetings}

Data collection on the leadership meetings started in August 2011 and continued until November 2014. During this time, the author, or sometimes another social scientist, observed 128 leadership meetings in total. Although the plan was to organize meetings each week, during summer and Christmas breaks, meetings were often cancelled. The meetings were always one hour long. 
The author arrived at the meetings some time before they began and stayed until all the participants had left the room. Therefore, it was possible to observe how leaders talked and interacted in and outside of the meeting context. In the meetings, the leaders were gathered around an oval-shaped table in a seminar room at the School of Medicine. When observing the meetings, the author sat around the same table taking notes, but without participating in the conversations. The author used her laptop to jot down and write up observations from the leaders' meeting interactions and conversations (Emerson et al., 1995). In addition to note taking, there was permission to record the meeting discussions. These recordings were extremely helpful during the analytical stage as they allowed for double-checking that the content of discussions was understood correctly.

\section{Interviews with leaders}

In addition to the meeting data, the five leaders and the administrator were interviewed at two different time points: when the center was formed and two years after. The first round of interviews was conducted by two researchers: the author and another researcher working on the project at the time. The author conducted the second round of interviews, two years after the formation of the center, alone.

On both rounds, the researchers relied on a semi-structured interview protocol, because the purpose was to obtain "descriptions of the life world of the interviewee in order to interpret the meaning of the described phenomena" (Kvale \& Brinkmann, 2008, p. 3). While each interviewee was asked the same general questions, there was flexibility in how the varied issues and topics they brought up were discussed in more detail. This allowed the different meanings that the interviewees assigned to leadership in the context of transdisciplinary science to surface. In other words, the interviewer asked different kinds of follow-up questions depending on how the informants responded to the planned questions (Corbin \& Strauss, 2015).

The interview protocol for the first round of interviews focused on how the transdisciplinary research center was planned and formed. The researchers asked questions, such as:

- What is your role in the premature birth center? How do you envision enacting this role in the center?

- What led you to current research on premature birth?

- What are the teams' and their members' roles as far as you can tell? What are they expected to do?

- Are there things researchers seem to agree on? What do they disagree on?

- Can you describe some concrete ways in which the research will get translated into medical practice?

The interview protocol for the second round of interviews was concerned with how the center had evolved during the first two years, what kind of scientific progress had been made, what transdisciplinary science looked like in practice, and what challenges the leaders had experienced since the formation of the center. The interview protocol included questions such as:

- How have you experienced the past couple of years that you have been part of the center?

- How would you describe your current tasks and responsibilities in the center?

- How have your responsibilities changed during the past two years?

- How has the center changed during the past couple of years?

- How and where do you interact with members of the center?

- How have you experienced the regularly organized meetings?

The length of each interview varied from 1 to 2 hours and they were transcribed by a transcription service. After each interview, the researchers also wrote summaries that helped with reflecting on the main themes covered in the interviews. 


\section{Analytical approach to meeting and interview data}

The analysis of the previously described meeting and interview data relating to the work of the leadership team is motivated by the theoretical and empirical observation that leadership plays an important role in knowledge creation processes (Bryant, 2003; Lakshman, 2007; Politis, 2002; Srivastava et al., 2006). Thus, while the study is explorative in many ways, it is not purely inductive (Glaser \& Strauss, 1967). Specifically, the author developed analytical codes that aligned with complexity leadership framework for uncovering how the leaders of transdisciplinary science mobilized and managed adaptive dynamics. The analysis of observation and interview data was done using Atlas.ti, a software for qualitative analysis.

The analysis of ethnographic field notes from leadership meetings and interviews with the leaders consisted of two stages that can be characterized as initial and focused coding (Lofland \& Lofland, 1995). During the initial coding stage, the author went through the 128 leadership meetings in chronological order and searched for evidence for different kind of leadership practices aimed at promoting transdisciplinary collaboration. These initial codes were defined for example as leadership practices aimed at developing a shared understanding of the problem of premature birth, engaging members in transdisciplinary conversations, and encouraging passive researchers to participate in research collaborations.

Before moving to the stage of focused coding, the author reviewed literature on leadership in knowledge-intensive organizations and used this prior research to make sense of the initial codes. This analytical stage required a modified grounded theory approach of comparison and contrast where the initial codes were compared against the complexity leadership theory framework (Strauss \& Corbin, 1990). Through an iterative process of reading literature and going through the initial codes, the author became convinced that the complexity leadership theory provided a useful framework for structuring the analytical coding of meeting observations even further. The leadership roles — enabling, adaptive or entrepreneurial, and administrative or operational—and their related practices thus provided a set of focused codes for winnowing out less useful initial codes and focusing in on a selected number of themes (Lofland \& Lofland, 1995; Uhl-Bien et al., 2007). This analytical process involved the identification of the three leadership roles and then connecting them with leadership practices present in the data (e.g., modelling transdisciplinary behavior, translation, brokering) (Uhl-Bien \& Arena, 2018; Uhl-Bien et al., 2007).

\section{Assessment of the method}

A longitudinal qualitative case study is appropriate for studying how the actions of leaders shape knowledge creation activities in complex adaptive systems. Such organizations are not stable and static. Rather, everything about them is emergent: leadership, relationships, networks, and knowledge. In addition, when leadership is seen as being distributed, shared, and processual, which is the case in complexity leadership theory, a longitudinal qualitative study can reveal how leadership evolves and transforms over time (Hollander, 1992; Hosking, 1988). When leadership is studied in the context of natural, situated activity, it can be seen as emerging through complex social dynamics and interactions (Uhl-Bien et al., 2007).

At the same time, by studying a single research organization, even if for a long time, it is not possible to produce generalizable findings. More broadly speaking, qualitative studies are not generalizable nor do they claim to be (Myers, 2000). Rather, the empirical findings, which will be discussed next, suggest ways in which leadership roles and practices might impact transdisciplinary science. In addition, they describe leaders of transdisciplinary science in a newly formed research organization. The challenges other leaders face can be different especially if their research organizations are established and hence at a different developmental stage. 


\section{ENABLING LEADERSHIP AND THE CREATION OF ADAPTIVE DYNAMICS}

In their efforts to create a context for transdisciplinary collaboration, the leaders emphasized the need to generate innovative ideas about premature birth that were different from existing lines of research. While the leaders thought it was important to have premature birth experts in the center, they also wanted to make sure that new research paths were emerging. Members of the center who had no experience with premature birth, but were included based on their analytical skills, were seen as particularly important for achieving this goal. These scientists could hopefully develop unexplored hypotheses about the health problem. They would help in making sure that the transdisciplinary center created new and innovative discoveries rather than produced traditional research outcomes due to the pressure to produce (Uhl-Bien \& Arena, 2018).

Adaptive dynamics are said to emerge from a given interactive context characterized by complex social dynamics and patterns of behavior that have the power to generate innovative outcomes (UhlBien et al., 2007). In the new transdisciplinary research center, the interactive context can be understood as shared weekly meetings, where members of the center came together to discuss research projects. In these meetings, researchers interacted, exchanged knowledge, and sought to produce transformative outcomes relating to premature birth.

In the following analysis, in addition to evidence from ethnographic fieldwork, I draw on quotes from interviews conducted with members of the leadership team. Each leader was given an identity number, which can be seen after the quote (e.g., ID-29).

\section{CONTEXT FOR ADAPTIVE DYNAMICS}

Immediately after the center was launched, the project meeting conversations were dominated by those premature birth experts who had spent their career researching and taking care of pregnant women and premature babies. The threat of falling back on creating knowledge through disciplinary approaches was real. One leader said, "It's easier to fall back into a traditional mold and do studies that look a lot like all the studies we've done before in our careers, and so it gives us the semblance of the perception of progress, of success because we're publishing" [ID-29]. Connected to this, the leaders felt the meeting conversations were focused on what was already known about the health problem:

They understand the problem according to the current paradigms. We don't know whether-well, the current paradigms have not been yielding with respect to solving the problem, right? We are missing something. That's why having a disposition that's focused on transdisciplinary discovery is so important. We want people to be open to new paradigms that would actually completely change the way you think about preterm birth...It's changing the paradigm that's really important in research to solving these kinds of problems. Until you change the paradigm and know the new rules and new operations, you can't solve the problem; you just spin within the existing paradigm. [ID27]

For transdisciplinary discovery to be successful, the leader thought it was important to separate the center's work from the current paradigms. To resist the influence of established lines of research, the leader emphasized that the center needed researchers who were "open to new paradigms." In fact, the leaders hoped that researchers would be able to internalize foreign research approaches to the extent that they would become unrecognizable to their home disciplines:

We want people to think beyond where they are routinely thinking. If [name of an epidemiologist] has never dealt with a biological question in the signaling pathway, we would want him to do that more often, ultimately. Same for [name of a pediatrician]. If 
I'm not used to dealing with the way they think, then I want to do that-I do enough of that, actually. I'm learning about their fields. Pretty soon, if you met me for the first time, you would think I might be an epidemiologist or something, but I'm not. That's sort of where we are headed is that I would be able to have multiple cloaks, and so would they, have multiple cloaks. What we are hoping is that the students who are in these environments will naturally wear multiple cloaks. [ID-27]

This leader used himself as an example. He said he was not initially familiar with epidemiology, but increasingly, due to his interactions and collaborations with an epidemiologist, an outsider would have a difficult time identifying his disciplinary background. The leaders wanted everyone in the center to experience this transformation and to become hybrid scholars. The interviewee described the learning process as being able to "wear multiple cloaks."

However, in order to initiate this process where existing expertise was broken down, rearranged, and then recombined to generate something different, the meeting participants had to begin to interact. One leader said the challenge was, how to connect different researchers' mental frameworks:

It is how you look at a problem. I think that what we are dealing with are different mental frameworks. The difficulty is how to appreciate what another person's mental framework would look like and how to get it to relate to your mental framework. [ID-8]

This cognitive incommensurability has been shown to prevent collaboration across knowledge boundaries in different ways (Cummings \& Kiesler, 2005; Dougherty, 1992; Lamont, 2009; Murray, 2010). While in the context of the transdisciplinary center there were multiple knowledge boundaries that needed to be crossed, the most challenging boundary was the one between premature birth experts and scientists with no prior experience with premature birth:

I mean, the science gets deep for them [practitioners] pretty fast. They probably understand some of it but not all of it, and maybe not enough to really react to what people are saying, and the reverse is certainly true. We have basic scientists in the room who really know very little about pregnancy and premature birth. [ID-23]

To summarize, when planning and mobilizing the transdisciplinary effort, the leaders emphasized the importance of creating a new paradigm for premature birth research, which required learning from others and valuing their research approaches. These kinds of adaptive goals called for enabling leadership practices, which could promote "interactions, interdependency, and adaptive tension to help motivate and coordinate the interactive dynamic" (Uhl-Bien et al., 2007, p. 309).

\section{ENABLING LEADERSHIP PRACTICES}

Complexity leadership theorists argue that enabling leadership practices are necessary for creating, protecting, and maintaining a space for adaptive dynamics (Uhl-Bien \& Arena, 2018). Relatedly, in order to create an environment where physicians, medical researchers, and scientists from different backgrounds could engage in learning and collaboration, the leaders of transdisciplinary science wanted to develop strategies for easing the crossing of knowledge boundaries. The leaders used modelling of transdisciplinary behavior and knowledge translation and brokering as their main enabling leadership practices.

\section{Modelling transdisciplinary behavior}

The leaders promoted transdisciplinary learning and collaboration by modelling transdisciplinary behavior. They hoped that this enabling leadership practice would build researchers' confidence towards independently taking part in transdisciplinary collaborative interactions. The regularly organized shared meetings were the best opportunity to influence the behavior of everyone involved with the center. The leaders believed that demonstrating how to interact in a transdisciplinary environment was particularly important for those who came from a science background. 
Traditionally, in medical science and sciences...the expression is that the more you can be expert at some tiny little field, the more likely you are to be very successful. Also, I think that the more you can present stuff that people can't understand, the more points you seem to get. If you can do a really terrific presentation so that people know that you really know what you're talking about, but they don't understand half of what you're saying, then that really builds your thing. [ID-8]

In a transdisciplinary environment, scientists had to demonstrate their expertise differently from the previous interviewee's description of typical seminar or conference behavior. The leaders were in a good position to demonstrate openness to new areas of knowledge to the other members of the organization. They were all established and respected scholars in their fields, so crossing disciplinary boundaries was not as risky for them as it was for junior researchers, for example. A leader who was in charge of leading a weekly data group was particularly effective in demonstrating to researchers how to interact across disciplinary boundaries. Occasionally, he even acted as a sort of rebellious academic and thought out loud ideas that many perceived as nontraditional.

I'm trying to push the envelope, so by example saying look, I'm willing to say stuff that maybe is outrageous and maybe it can stimulate something. Other people may be more timid about saying things that they feel might make them look non-expert or look foolish or something like that. Part of it, maybe they are not trained to do that, to make those jumps. [ID-8]

By being active in the meeting settings and expressing untraditional ideas, the leader hoped he could support intellectual risk taking in others. Indeed, risk taking, experimentation, flexibility, and play are important activities in complex adaptive systems and they should be promoted through enabling leadership (March, 1991; Uhl-Bien \& Arena, 2018).

One leader noted, however, that even after their efforts to model transdisciplinary behavior, it still tended to be more common among the senior researchers than the junior researchers to engage in transdisciplinary discussion. Senior researchers seemed to be more at ease in transdisciplinary meetings. Of course, from the perspective of academic careers, the tenured senior scholars had less to lose than the junior scholars.

I think it is the more senior people who talk comfortably to each other, but it is sort of like demonstrating. It is sort of like showing - it is like kids watching their parents. The kids are modeling. If the scientists are modeling their interactions, in a way, then I think the students learn that that's the way it should be done. That's where you are going to get productivity. It's okay, actually, to ask these questions. 'Look at my mentor getting quizzed by [name of a senior scholar] and [name of a senior scholar]', you know? Or, 'Look at my mentor asking a question back to them which is getting them to say something that we don't really think about.' Once they get used to that, then it will be easier for the next generation to do these things, I think. It is modeling. [ID-27]

Although this modelling did not engage everyone in transdisciplinary conversation immediately, this leader was not concerned. He perceived it as seniors modelling transdisciplinary interactions to juniors, like "kids watching their parents." The hope was that over time the junior scholars would learn to participate in transdisciplinary thinking, ask questions, and share their expertise.

\section{Translation and brokering}

Over the course of the first six months, the leaders discovered that modelling transdisciplinary behavior was not enough for initiating learning and collaboration within the center. One leader said they had to continue to guide and manipulate collaborative interactions: "Transdisciplinary discussion has not evolved spontaneously. A little bit, but I think it really still requires a lot of manipulation or guidance" [ID-8]. Therefore, the leaders began to rely on another enabling leadership practice: knowledge translation and brokering. Arena and Uhl-Bien (2016) have pointed out that enabling 
leaders can establish adaptive space by brokering and bringing individuals together. In the transdisciplinary research organization, the shared meetings brought members of the center together physically, but knowledge translation and brokering were needed to connect actors intellectually. The leaders practiced these connecting activities both in and outside of meetings (Uhl-Bien \& Arena, 2018).

One-on-one interactions between a leader and a member of the transdisciplinary research community were important when the center was formed and nobody knew each other, or when new researchers joined the effort. These interactions allowed the leaders to get to know the specific researchers and get a sense of what their expertise was like. As a consequence, they could make plans for how to integrate a researcher with particular expertise to ongoing research projects. Once the leader had an understanding of what the researcher was able to do, he could translate this expertise to the other members of the center. One leader explained how he approached a researcher who had recently joined the center:

Like, I asked [name of a scientist], I said, 'Tell me what you are doing in more detail, like a paragraph,' so he sent it to me. I have that; no one else has that yet. I had a sense of what he was doing from what he told me, and I said, 'Well, do you have papers that you have published?' 'No.' I said, 'Well, then, tell me yourself, in your own words, in about a paragraph what you do.' I will take that and I will then massage that in a way that begins to make sense to other people. I will translate what he is doing into their worlds. [ID-27]

This example demonstrates the work the leaders did as translators. First, the leader familiarized himself with the work of the researcher, and then introduced his work to others whose projects might benefit from the new researcher's input. The leader invited the researcher to attend particular project meetings, supported his presence in the meeting, and suggested ways in which he could contribute to the project.

The translation work continued in every interaction the leader had with members of the center. $\mathrm{He}$ wanted to understand how the researchers typically approached research problems and then tried to guide them to think in new ways. This practice can be perceived as "injecting tension into the system," which is one strategy for opening up the adaptive space (Uhl-Bien \& Arena, 2018, p. 11). The leader had to do this delicately so as not to create too much tension and conflict between differing perspectives.

When I interact with people, I want to know what they are thinking about. I will ask them questions like, 'How do you think that relates to such-and-such?' and then let them think out loud about it. If they are comfortable, they will think about it. They may not necessarily say, 'Well, I have got a bit of an idea.' Instead, I will say, 'Well, did you ever think about this?' and then they will say, 'Hmm, interesting' and it goes from there. [ID-27]

While in the shared meetings, researchers' different ways of doing research and thinking about premature birth sometimes clashed, the one-on-one conversations between a leader and a researcher had a different tone. The leader did not challenge the researcher's work, but rather expressed interest in it and suggested new ways of approaching it. Similarly to modelling transdisciplinary behavior in shared meetings, the leader demonstrated how researchers from different backgrounds could interact without too much confrontation.

In addition to this behind the scenes translation work, the leaders acted as knowledge brokers in the shared meetings. Uhl-Bien and Arena (2018, p. 12) have noted that "connecting involves linking up agents (i.e., ideas, information, people, resources, technology) in ways that scale novelty and innovation into beneficial new order in the operational system." In line with this, the leaders developed brokering tactics to connect the different individuals and their perspectives. 
The challenge was that while in private conversations the leaders could motivate researchers to talk about their work, in the shared meetings many researchers became silent. This was because in the heterogeneous project meetings, the conversation could go in multiple directions and include topics a researcher was not familiar with. As this leader described: "You just talk to people about the things that they are good at doing, then they will talk about them easily. If you talk about things they don't do on a regular basis, they don't talk" [ID-27]. As such, the leaders sought to first activate individuals who were more silent in order to make sure that different perspectives were heard. This was easier when the leaders were leading the meeting. This leader, for example, was in charge of leading a data group:

I saw my role as to try to at least foster transdisciplinary discussion around whatever we were doing. I tried, and this has evolved over time, to provoke transdisciplinary discussion either by calling on people or asking questions or to try to get people involved to get the transdisciplinary perspective. [ID-8]

When heading the meeting, this leader relied on tactics such as calling on people and asking them questions. In this way, the meeting conversations included more perspectives. The next step was to connect different individuals or groups at a concrete level to actually work on something together:

I see that as an important role, trying to promote transdisciplinary thought and trying to get people linked up. Often I will try to suggest that maybe two projects that are doing things that are different, but could combine them, would actually work together or at least to think something out. That's just starting to emerge. I have been trying to do that for a long time, but I think it's finally starting to come together...I think that building a transdisciplinary team takes a long time. [ID-8]

The leader paid attention to everyone present in the project meetings he led. He made sure participants were active and made connections with others in the room.

The interview where the previous quote is from was conducted two years after the formation of the center. Still, the interviewee said that transdisciplinary thought was "just starting to emerge." This highlights how much time and effort the leaders had to put into mobilizing new transdisciplinary research collaborations. While the discussed enabling leadership practices were critical for this work, their benefits did not materialize immediately. Unlearning disciplinary training was not something that could be achieved in a short period of time.

\section{ADMINISTRATIVE AND OPERATIONAL LEADERSHIP AND THE MANAGEMENT OF TRANSDISCIPLINARY SCIENCE}

The described enabling leadership practices were crucial for jumpstarting learning and collaboration, but demanded that the leaders take a central role in the management of transdisciplinary science. When the leaders brokered researchers and projects, they identified promising projects, decided on how research resources were used, and provided roles for collaborators (Hazy \& Uhl-Bien, 2013). In complexity leadership theory, these practices are associated with administrative or operational leadership (Uhl-Bien \& Arena, 2018; Uhl-Bien et al., 2007). This section discusses the delicate relationship between different leadership roles and suggests that an imbalance in this relationship can prevent some actors from contributing to research collaborations and thus can jeopardize the creation of adaptive dynamics.

Enabling leadership practices began to shift towards administrative leadership, when an increasing number of researchers became interested in the transdisciplinary research organization. As research funds from the NIH were difficult to get, medical researchers and scientists, beyond those initially included in the effort, began to show interest in the transdisciplinary study of premature birth. The center had a biweekly research seminar, where researchers outside the center could come pitch their 
research ideas to the leadership team. One leader explained that the increased interest in the center's premature birth grant forced them to deal with an overabundance of promising research ideas:

Having funding from a foundation and having restricted funds on the NIH side actually makes it a little bit more likely that investigators that were otherwise perfectly fine and happy, because they had plenty of money, are now headed in this direction to see if they can find money to do work, right? That's an irony of the circumstance, which actually provides incentive to people to congregate and begin to work on this [transdisciplinary study of premature birth]... The trouble is, we don't have enough money to incent everybody. They can come and present a great idea, and then the next thing they want is money, and we don't have enough. [ID-27]

The leader was pleased that researchers from different fields were interested in the premature birth research center and proposed ideas for how to study the syndrome. However, there was not enough money to support every project, no matter how promising the research ideas were. Ultimately, the leaders had to decide what was worth funding, which was a great responsibility in a situation where nobody knew what was causing premature birth.

Furthermore, while premature birth seemed like a narrow research problem, there were actually multiple different research paths that could have been taken to create new knowledge on the topic. The leaders had to make sure there was a sense of direction for the research effort, otherwise it would be challenging to make progress. Here is how one leader explained it:

The biggest problem is that every [research] avenue looks exciting, right? It looks 'oh my God, it's so interesting.' The leadership group, our job is to try and be sure that we keep the train going forward because otherwise we are going to be going like this [gestures a circle]. That's difficult because everything's exciting. Everything looks great, but you have to be able to keep focus and try to bring it all together. [ID-7]

One strategy for keeping "the train going forward," as the leader said, was the initial decision to focus on four transdisciplinary research projects. These projects were selected by the leaders already before the center was formed. But as these projects led to discoveries, new research avenues began to emerge. In many ways, this development could be seen as something positive. Multiple interesting research avenues could be signs of intellectual chaos that could lead to more creativity and development (Nonanka \& Yamanouchi, 1989). But again, the leaders had to make decisions about which research ideas were worth the limited resources they had. One leader confessed that they had made some mistakes along the way:

We have to think about, practically speaking, what are the synergies that we might fund? What are the people that are likely to actually work well together and make choices that reflect that? So far we are doing okay, but we have made some mistakes, too.... It's selfserving their goals in trying to understand [referring to a project on infection and premature birth], which is what [a scientist] is interested in. It's just not engaging enough for a lot of the people, so that's money that we spent that probably is going to go nowhere. Now, it might ultimately get her a grant and it might get him a few papers, but I am not sure it's going to contribute much to premature birth, to be blunt. [ID-27]

The leaders did not want to pick projects only on the basis of what was a promising idea. They wanted to identify researchers who were able to work with others and create collaborative synergies across the center and its projects. They wanted researchers who were "open to new paradigms," as was noted previously. While the leader said they were "doing okay" in their attempt to support the best possible projects, they had also made some mistakes. One project they had decided to fund was helping the individual scholar and her career, but not necessarily creating knowledge that would contribute to solving the health problem. 
There was one leader who reflected on the administrative and operational power the leadership team had. He acknowledged that they were not only overseeing transdisciplinary research, but also making decisions about the research direction in a way that was not transparent to the whole community.

Although, I think that the leadership committee is not only overseeing the general direction of the projects, but also cutting deals with prospective investigators kind of behind the doors. Whether this is a good thing or a bad thing, I don't know, but it's probablyit's not transparent. [ID-8]

Administrative leadership can help in assuring that organizationally-prescribed outcomes are effectively achieved (Uhl-Bien et al., 2007). Yet, when a complex adaptive system relies on administrative leadership too heavily, the relationship between different leadership functions can become unbalanced, which can threaten the creation of adaptive dynamics. Moreover, prior research on organizational knowledge creation has noted that the power to say what is relevant and valuable knowledge should not be given to a few individuals in formal leadership positions (Essers \& Schreinemakers, 1997; Gourlay, 2006). In the context of the transdisciplinary research organization, the leadership team was in a position to guide knowledge creation toward directions that they selected based on their knowledge of premature birth research, new discoveries from ongoing projects, and synergies among members of the center. While this behavior may have guaranteed the production of research outcomes, the adaptive dynamics suffered from a lack bottom-up processes, such as experimentation (Uhl-Bien \& Arena, 2018).

\section{DISCUSSION: ESTABLISHING ENTANGLEMENT AND INTERDEPENDENCY IN A NEW TRANSDISCIPLINARY ENVIRONMENT}

Complexity leadership theory provides a useful framework for analyzing how leaders of transdisciplinary science try to mobilize and manage collaboration across disciplinary boundaries. By identifying different kinds of leadership roles and observing how they are implemented in practice, this study was able to provide insights on the role of academic leaders in a newly formed transdisciplinary environment. In this concluding discussion, I reflect on the challenges for establishing entanglement of leadership functions and interdependency among organizational members in a new research center. Furthermore, I discuss how the lack of entanglement and interdependency can be used to explain why the leaders became the focal points of knowledge creation.

Complexity leadership theory emphasizes that while administrative or operational, enabling, and adaptive or entrepreneurial leadership roles can be identified as distinct forms of leadership, effectively functioning organizations need them to work together (Hazy \& Uhl-Bien, 2013; Uhl-Bien \& Marion, 2009; Uhl-Bien et al., 2007). Ideally, these different forms of leadership exist in a dynamic relationship - they are entangled together-and in this way support the creation of adaptive dynamics in complex systems. Rather than existing independently, different leadership functions and their interactions become entangled throughout the complex adaptive system (Lottrecchiano, 2010). In the context of the transdisciplinary research organization, it seemed that the different leadership functions were not sufficiently entangled. Instead, they formed a kind of leadership toolbox from where the leaders selected a function and related leadership practices that suited a given situation.

In addition to weak entanglement of the different leadership functions, the leaders had a difficult time with fostering interdependency among the members of the transdisciplinary research center. Uhl-Bien et al. (2007, p. 310) noted: "While interaction permits the movement and dynamic interplay of information, interdependency creates pressure to act on information." The goal of increasing information flow in a complex adaptive system is not enough (Uhl-Bien et al., 2007). Experts need to develop interdependency among themselves so there is a real incentive to collaborate. The leaders relied on practices that fostered the movement and interplay of different types of expertise in shared 
meetings, but in the new research organization the researchers were not immediately dependent on each other. The researchers may have had developed interdependency in their more disciplinary projects with their existing collaborators or graduate students. However, in the transdisciplinary research center, where collaborative relationships between people were not yet established, it was not clear where interdependencies could develop or where they were even necessary.

The empirical findings reveal how weak entanglement of leadership functions and lack of interdependency among members of the organization can challenge the creation of adaptive dynamics throughout the organization. Immediately after the center was formed, the leaders were eager to support the creation of adaptive dynamics by relying on enabling leadership practices. They saw value in connecting activities, which are known to be crucial for the facilitation of adaptability and change in complex adaptive systems (Arena et al., 2017; A. Taylor \& Helfat, 2009; Uhl-Bien \& Arena, 2018). In a new transdisciplinary research organization, knowledge brokering and translation were particularly important, because most of the collaborators were not familiar with each other or the problem of premature birth.

Yet, quite quickly, the leaders faced a situation where there was a pressure to produce results. Transdisciplinary research organizations - especially when they are just established and have not yet developed stable knowledge creation processes — can struggle with jumpstarting collaborations that can lead to innovative research outcomes. The risk tends to be that the pressure to produce products comes in the way of the need to innovate (Uhl-Bien \& Arena, 2018). In this situation, in order to ensure transdisciplinary research outcomes, the leaders began to rely on an administrative leadership role.

These challenges - connecting members in the new center and ensuring that progress was madeand the leaders' responses to them made the leaders the focal point of transdisciplinary knowledge integration (see Figure 1.). First, when the leaders translated and brokered knowledge in line with enabling leadership, they became knowledgeable of all the expertise present in the center. Second, they used the gained knowledge to broker expertise and people on transdisciplinary research projects. Third, they assessed research ideas and decided which projects to support.

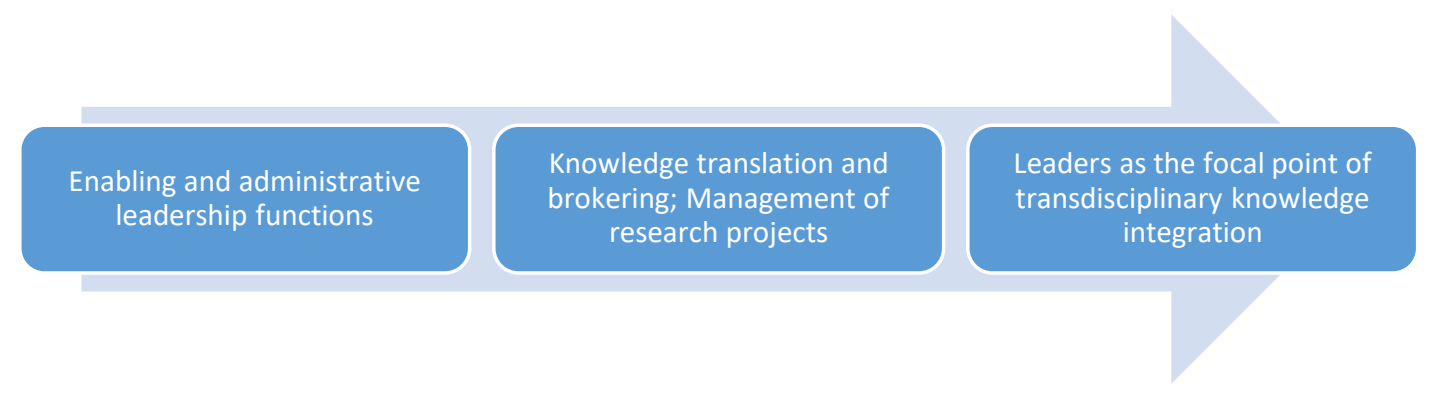

Figure 1. Leadership roles, practices, and point of transdisciplinary knowledge integration

Leaders becoming the focal point of knowledge integration has consequences for a system's adaptive dynamics. Lotrecchiano (2010) has stated that successful transdisciplinary environments require knowledge feedback loops that run throughout the organization on multiple levels. If formal leaders act as the focal points of knowledge integration, the knowledge feedback loop is not likely to draw on the expertise of all organizational members in an optimal way. Similarly, in relation to facilitating adaptive processes, Uhl-Bien and Arena (2018) emphasize the importance of both top-down and bottom-up processes, which need to be integrated in a dynamic way.

It is important to remember, though, that the empirical context of the present study sheds light on the challenges of building adaptive dynamics in a new transdisciplinary center. Despite the tendency of the leaders to take charge of transdisciplinary knowledge creation in these early stages, the center's future with regards to transdisciplinary success remains to be seen. In other words, the discussed findings increase our understanding of what goes on in recently established transdisciplinary envi- 
ronments, but they do not presume a long-term outcome for the center. This is reasonable given that the developmental path from basic science to new medical solutions is slow and can take up to fifteen years (Balas \& Boren, 2000; Contopoulos-Ioannidis, Alexiou, Gouvias, \& Ioannidis, 2008). Although in this empirical setting the leaders became the focal points of knowledge integration, over time with more collaboration experience, familiarity, and trust among all members of the center, transdisciplinary collaboration at all organizational levels is likely to become easier.

There is also much to be learned from the present study on how to mobilize transdisciplinary collaboration in a new center. This study suggests that knowledge brokers capable of interacting at knowledge boundaries should be spread throughout the organization in strategic positions. A study on brokering activities in the area of patient safety by Waring et al. (2013) showed that those in more informal roles can be more effective at knowledge brokering, because they rely less on bureaucratic authority and more on professional and relational qualities. The leaders of the transdisciplinary research center could have recruited team leaders who were skillful at knowledge brokering. These individuals would have been in a position to form connections across projects and to generate interdependency more easily than the formal leaders.

\section{CONCLUSION}

Transdisciplinary research organizations are complex adaptive systems in the sense that they bring together actors from varied backgrounds, promote interdependence among them, and form dynamic collectives with common goals (Cilliers, 1998; Lotrecchiano, 2010; Marion, 1999). This study examined what kind of leadership roles and practices academic leaders of transdisciplinary science rely on when they seek to promote adaptive dynamics. The study utilized complexity leadership theory framework, because it provided analytical tools for understanding the role of leaders in emergent collaborative contexts (Hazy \& Uhl-Bien, 2013; Uhl-Bien \& Marion, 2009; Uhl-Bien et al., 2007).

The study revealed that although academic leaders rely on different types of leadership practices, in an emergent collaborative context, finding an optimal balance between them is challenging. When the center was formed, the leaders drew on practices related to enabling leadership. Later on, however, they took on a more administrative role as there was an increasing pressure to show transdisciplinary progress. The leaders decided on promising research ideas, how resources were used, and assigned researchers on projects. I argued that the use of such top-down leadership practices made the leaders the focal point of transdisciplinary knowledge integration. This, in turn, created an obstacle for the creation of shared adaptive dynamics throughout the research organization.

While the findings reveal what the creation of adaptive dynamics in a new transdisciplinary research center can look like from the perspective of leadership, it does not describe challenges other leaders might face in different organizational contexts or at different developmental stages in the transdisciplinary knowledge creation process. Future research will have to address this question.

\section{REFERENCES}

Abbott, A. (2001). Chaos of disciplines. Chicago, IL: University of Chicago Press.

Arena, M., Cross, R., Sims, J., \& Uhl-Bien, M. (2017). Groundswell: Tapping the power of employee networks to fuel emergent innovation. MIT Sloan Management Review, 58(4), 39-47.

Balas, E. A. \& Boren, S. A. (2000). Managing clinical knowledge for healthcare improvement. In J. Bemmel \& A. T. McCray (Eds.), Yearbook of medical informatics (pp. 65-70).

Barge, J. K. \& Musambira, G. W. (1992). Turning points in chair-faculty relationships. Journal of Applied Communication, 20, 54-77. https://doi.org/10.1080/00909889209365319

Bechky, B. A. (2003). Sharing meaning across occupational communities: The transformation of understanding on a production floor. Organization Science, 14(3), 312-330. https://doi.org/10.1287/orsc.14.3.312.15162 
Biancani, S., McFarland, D. A., \& Dahlander, L. (2014). The semiformal organization. Organization Science, 25(5), 1306-1324. https://doi.org/10.1287/orsc.2013.0882

Boix Mansilla, V. (2006) Interdisciplinary work at the frontier: An empirical examination of expert interdisciplinary epistemologies. Issues in Integrative Studies, 24, 1-31.

Bolden, R. (2011). Distributed leadership in organizations: A review of theory and research. International Journal of Management Reviews, 13, 251-269. https://doi.org/10.1111/j.1468-2370.2011.00306.x

Bryant, S. E. (2003). The role of transformational and transactional leadership in creating, sharing and exploiting organizational knowledge. Journal of Leadership and Organizational Studies, 9, 32-44. https://doi.org/10.1177/107179190300900403

Bryman, A. (2007). Effective leadership in higher education: A literature review. Studies in Higher Education, 32(6), 693-710. https://doi.org/10.1080/03075070701685114

Cilliers, P. (1998). Complexity and postmodernism. Understanding complex systems. London, UK: Routledge.

Contopoulos-Ioannidis, D. G., Alexiou, G. A., Gouvias, T. C., \& Ioannidis, J. P. A. (2008). Life cycle of translational research for medical interventions. Science, 321(5894), 1298-1299. https://doi.org/10.1126/science.1160622

Corbin, J., \& Strauss, A. (2015). Basics of qualitative research: Techniques and procedures for developing grounded theory. Thousand Oaks, CA: Sage.

Cummings, J. N., \& Kiesler, S. (2005). Collaborative research across disciplinary and organizational boundaries. Social Studies of Science, 35(5), 703-722. https://doi.org/10.1177/0306312705055535

Dervitsiotis, K. N. (2005). Creating conditions to nourish sustainable organizational excellence. Total Quality Management \& Business Excellence, 16(8, 9), 925-943. https://doi.org/10.1080/14783360500163078

Dess, G., \& Picken, J. C. (2000). Changing roles: Leadership in the 21st century. Organizational Dynamics, 28(3), 18-34. https://doi.org/10.1016/S0090-2616(00)88447-8

Dougherty, D. (1992). Interpretive barriers to successful product innovation in large firms. Organization Science, 3(2), 179-202. https://doi.org/10.1287/orsc.3.2.179

Drath, W. (2001). The deep blue sea: Rethinking the source of leadership. San Francisco, CA: Jossey-Bass and Center for Creative Leadership.

Emerson, R., Fretz, R., \& Shaw, L. (1995). Writing ethnographic fieldnotes. Chicago, IL: University of Chicago Press. https://doi.org/10.7208/chicago/9780226206851.001.0001

Essers, J. \& Schreinemakers, J. (1997). Nonaka's subjectivist conception of knowledge in corporate knowledge management. Knowledge Organization, 24, 24-32.

Gibbons, M., Limoges, C., Nowotny, H., Schwartzman, S., Scott, P., \& Trow, M. (1994). The new production of knowledge: The dynamics of science and research in contemporary societies. London, UK: Sage.

Glaser, B. G., \& Strauss, A. L. (1967). The discovery of grounded theory: Strategies for qualitative research. Chicago, IL: Aldine Transaction Publishers.

Gourlay, S. (2006). Conceptualizing knowledge creation. A critique of Nonaka's theory. Journal of Management Studies, 43, 1415-1436. https://doi.org/10.1111/j.1467-6486.2006.00637.x

Haas, M. R. (2016). Acquiring and applying knowledge in transnational teams: The roles of cosmopolitans and locals. Organization Science, 17(3), 367-384. https://doi.org/10.1287/orsc.1060.0187

Hargadon, A. (2003). How breakthroughs happen. Cambridge, MA: Harvard Business School Press.

Hazy, J. K. (2007). Computer models of leadership: Foundation for a new discipline or meaningless diversion? Leadership Quarterly, 18(4), 391-410. https://doi.org/10.1016/j.leaqua.2007.04.007

Hazy, J. K., \& Uhl-Bien, M. (2013). Towards operationalizing complexity leadership: How generative, administrative and community-building leadership practices enact organizational outcomes. Leadership, 11(1), 79104. https://doi.org/10.1177/1742715013511483 
Mäkinen

Heifetz, R. A. (1994). Leadership without easy answers. Cambridge, MA: Harvard University Press.

Heifetz, R. A. \& Linsky, M. (2002). Leadership on the line: Staying alive through the dangers of leading. Boston, MA: Harvard University Press.

Hollander, E. P. (1992). The essential interdependence of leadership and followership. Current Directions in Psychological Science, 1(2), 71-75. https://doi.org/10.1111/1467-8721.ep11509752

Hosking, D. M. (1988). Organizing, leadership and skillful process. Journal of Management Studies, 25(2), 147-166. https://doi.org/10.1111/j.1467-6486.1988.tb00029.x

Huising, R. (2014). The erosion of expert control through censure episodes. Organization Science, 25(6), 16331661. https://doi.org/10.1287/orsc.2014.0902

Jacobs, J. A., \& Frickel, S. (2009). Interdisciplinarity: A critical assessment. Annual Review of Sociology, 35, 43-65. https://doi.org/10.1146/annurev-soc-070308-115954

Kellogg, K. C. (2014). Brokerage professions and implementing reform in age of experts. American Sociological Review, 79(5), 912-941. https://doi.org/10.1177/0003122414544734

Klein, J. T. (1990). Interdisciplinarity: History, theory, and practice. Detroit, MI: Wayne State University Press.

Kontopoulos, K. M. (1993). The logics of social structure. Cambridge, MA: Cambridge University Press. https://doi.org/10.1017/CBO9780511570971

Kunda, G. (1992). Engineering culture: Control and commitment in a bigh-tech corporation. Philadelphia, PA: Temple University Press.

Kvale, S., \& Brinkmann, S. (2008). InterViews: Learning the craft of qualitative research interviewing (2nd ed.). Thousand Oaks, CA: Sage.

Lakshman, C. (2007). Organizational knowledge leadership: A grounded theory approach. Leadership \& Organization Development Journal, 28, 51-75. https://doi.org/10.1108/01437730710718245

Lamont, M. (2009). How professors think: Inside the curious world of academic judgment. Cambridge, MA: Harvard University Press. https://doi.org/10.4159/9780674054158

Langley, A. (1999). Strategies for theorizing from process data. Academy of Management Review, 24, 691-710.

Lichtenstein, B., Uhl-Bien, M., Marion, R., Seers, A., Orton, D., \& Schreiber, C. (2006). Leadership in emergent events: Exploring the interactive process of leading complex situations. Emergence: Complexity and Organization, 8(4), 2-12.

Lofland, J., \& Lofland, L. H. (1995). Analyzing social settings. A guide to qualitative observation and analysis. Belmont, CA: Wadsworth Publishing Company.

Lomas, J. (2007). The in-between world of knowledge brokering. British Medical Journal, 334(7585), 129-132. https://doi.org/10.1136/bmj.39038.593380.AE

Lotrecchiano, G. R. (2010). Complexity leadership in transdisciplinary (TD) learning environments: A knowledge feedback loop. International Journal of Transdisciplinary Research, 5(1), 29-63.

Lotrecchiano, G. R. (2014). Defining collaboration science in an age of translational medicine. Journal of Translational Medicine and Epidemiology, 2(2), 1023.

Maasen, S., \& Lieven, O. (2006). Transdisciplinarity: A new mode of governing science? Science \& Public Policy, 33(6), 399-410. https://doi.org/10.3152/147154306781778803

Majchrzak, A., More, P. H. B., \& Faraj, S. (2012). Transcending knowledge differences in cross-functional teams. Organization Science, 23(4), 951-970. https://doi.org/10.1287/orsc.1110.0677

March, J. G. (1991). Exploration and exploitation in organizational learning. Organization Science, 2(1), 71-87. https://doi.org/10.1287/orsc.2.1.71

Marion, R. (1999). The edge of organization: Chaos and complexity theories of formal social organizations. Newbury Park, CA: Sage. 
Marion, R., \& Uhl-Bien, M. (2001). Leadership in complex organizations. Leadership Quarterly, 12, 389-418. https://doi.org/10.1016/S1048-9843(01)00092-3

Murray, F. (2010). The oncomouse that roared: Hybrid exchange strategies as a source of distinction at the boundary of overlapping institutions. American Journal of Sociology, 116(2), 341-388. https://doi.org/10.1086/653599

Myers, (2000). Qualitative research and the generalizability question: Standing firm with Proteus. The Qualitative Report, 4(3), 3-4.

Mäkinen, E. I. (2015). Meetings of the minds. Knowledge integration processes in transdisciplinary science. Ph.D. Thesis. Stanford University.

Nag, R., Corley, K. G., \& Gioia, D. A. (2007). The intersection of organizational identity, knowledge, and practice: Attempting strategic change via knowledge grafting. Academy of Management Journal, 50(4), 821-847. https://doi.org/10.5465/AMJ.2007.26279173

Nonanka, I., \& Yamanouchi, T. (1989). Managing innovation as a self-renewing process. Journal of Business Venturing, 4, 299-315. https://doi.org/10.1016/0883-9026(89)90003-7

Owen-Smith, J. (2001). Managing laboratory work through skepticism: Processes of evaluation and control. American Sociological Review, 66(3), 427-452. https://doi.org/10.2307/3088887

Pearce, C., \& Sims, H. (2000). Shared leadership: Toward a multi-level theory of leadership. In M. Beyerlein, D. Johnson, \& S. Beyerlein (Eds.), Advances in the interdisciplinary studies of work teams, Volume 7 (pp. 115-139). New York, NY: JAI. https://doi.org/10.1016/S1572-0977(00)07008-4

Politis, J. D. (2002). Transformational and transactional leadership enabling (disabling) knowledge acquisition of self-managed teams: The consequences for performance. Leadership \& Organization Development Journal, 23, 186-197. https://doi.org/10.1108/01437730210429052

Schneider, M., \& Somers, M. (2006). Organizations as complex adaptive systems: Implications of complexity theory for leadership research. Leadership Quarterly, 17(4), 351-365. https://doi.org/10.1016/i.leaqua.2006.04.006

Schwartzman, H. B. (1989). The meeting: Gatherings in organizations and communities. New York, NY: Plenum Press. https://doi.org/10.1007/978-1-4899-0885-8

Shrum, W., Genuth, J., \& Chompalov, I. (2007). Structures of scientific collaboration. Cambridge, MA: The MIT Press.

Sonnenwald, D. H. (2007). Scientific collaboration. Annual Review of Information Science and Technology, 41, 643681. https://doi.org/10.1002/aris.2007.1440410121

Srivastava, A., Bartol, K., \& Locke, E. A. (2006). Empowering leadership in management teams: Effects on knowledge sharing, efficacy, and performance. Academy of Management Journal, 49, 1239-1251. https://doi.org/10.5465/AMJ.2006.23478718

Stevenson, D. K., Shaw, G. M., Wise, P. H., Norton, M. E., Druzin, M. L., Valantine, H. A., \& McFarland, D. A. (2013). Transdisciplinary translational science and the case of preterm birth. Journal of Perinatology, 33, 251258. https://doi.org/10.1038/jp.2012.133

Strauss, A. L. \& Corbin, J. M. (1990). Basic of qualitative research: Grounded theory procedures and techniques. Newbury Park, CA: Sage.

Taylor, A., \& Helfat, C. E. (2009). Organizational linkages for surviving technological change: Complementary assets, middle management, and ambidexterity. Organization Science, 20(4), 718-739. https://doi.org/10.1287/orsc.1090.0429

Taylor, B. C., \& Trujillo, N. (2001). Qualitative research methods. In F. Jablin \& L. Putnam (Eds.), The new handbook of organizational communication: Advances in theory, research, and methods (pp. 161-194). Thousand Oaks, CA: Sage. https://doi.org/10.4135/9781412986243.n5

Uhl-Bien, M. (2006). Relational leadership theory: Exploring the social processes of leadership and organizing. Leadership Quarterly, 17(6), 654-676. https://doi.org/10.1016/j.leaqua.2006.10.007 
Uhl-Bien, M. \& Arena, M. (2018). Leadership for organizational adaptability: A theoretical synthesis and integrative framework. Leadership Quarterly, 29(1), 89-104. https://doi.org/10.1016/j.leaqua.2017.12.009

Uhl-Bien, M. \& Marion, R. (2009). Complexity leadership in bureaucratic forms of organizing: A meso model. Leadership Quarterly, 20(4), 631-650. https://doi.org/10.1016/j.leaqua.2009.04.007

Uhl-Bien, M., Marion, R., \& McKelvey, B. (2007). Complexity leadership theory: Shifting leadership from the industrial age to the knowledge era. Leadership Quarterly, 18(4), 298-318. https://doi.org/10.1016/j.leaqua.2007.04.002

Ward, V., House, A., \& Hamer, S. (2009). Knowledge brokering: The missing link in the evidence to action chain? Evidence \& Policy, 5(3), 267-279. https://doi.org/10.1332/174426409X463811

Waring, J., Currie, G., Crompton, A., \& Bishop, S. (2013). An exploratory study of knowledge brokering in hospital settings: Facilitating knowledge sharing and learning for patient safety? Social Science \& Medicine, 98, 79-86. https://doi.org/10.1016/i.socscimed.2013.08.037

Yin, R. K. (2009). Case study research: Design and methods. London, UK: Sage.

Yukl, G. A. (2005). Leadership in organizations (6th ed.). Englewood Cliffs, NJ: Prentice Hall.

Ziman, J. (1996). Postacademic science: Constructing knowledge with networks and norms. Science Studies, 1, 6780 .

\section{BIOGRAPHY}

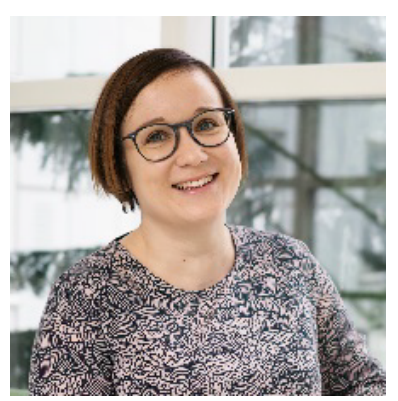

Elina I. Mäkinen is an organizational researcher specializing in innovation, collaboration, and teamwork in the life sciences. A major part of Dr. Mäkinen's research focuses on understanding the varied challenges for transdisciplinary team science. She received her Ph.D. at Stanford University's organization studies doctoral program. She has worked as a postdoctoral research fellow at the Faculty of Management and at the Institute for Advanced Social Research at University of Tampere, Finland. She was recently appointed as an associate professor in the New Social Research Program at University of Tampere. 